\title{
O processo de formação de professores por meio da educação a distância: uma experiência pioneira
}

\section{The teacher training process through distance education: a pioneer experience}

\author{
Oscar Massaru Fujita ${ }^{1}$, Ronaldo José Nascimento ${ }^{2}$, Pedro Paulo da Silva Ayrosa ${ }^{3}$, \\ Dirceu Moreira Guazzi ${ }^{4}$
}

\begin{abstract}
Resumo
O presente texto expõe de forma sucinta as ações realizadas no processo de formação e as parcerias estabelecidas para a concretização do pioneiro processo educacional de cursos na modalidade Educação a Distância (EaD) da Universidade Estadual de Londrina (UEL-PR). O delineamento metodológico foi desenvolvido segundo a Abordagem Qualitativa do tipo Pesquisa-Ação, que prioriza o desenvolvimento e a análise do processo juntamente com o "significado" que as pessoas dão às coisas e à sua vida do que propriamente o produto em si. Os dados coletados por meio dos questionários aplicados ao final do curso sinalizam as impressões (positivas e críticas construtivas) que recebemos e os significados que cursistas vivenciaram (depoimentos, chats, fóruns de discussão, projetos) nos cursos oferecidos. A experiência vivenciada nestes três cursos: Ambiente Virtual de Aprendizagem (60 horas); Tutoria em EaD (60 horas) e Material Didático em EaD (60 horas), desde a sua concepção até a sua efetiva conclusão, nos fazem pensar que estamos no caminho certo e que por meio das TDIC, novos horizontes podem se abrir para a instituição a curto e a médio prazo.
\end{abstract}

Palavras-chaves: Formação de professores. Educação a distância. Metodologia e estratégias didáticas. Tecnologias de informação e comunicação. Ambiente virtual de aprendizagem.

\begin{abstract}
This paper presents briefly the actions conducted in the formation process and established partnerships to achieve the pioneering educational process of Distance Education (DE) courses of the State University of Londrina (UEL-PR). The methodological design was developed according to the Qualitative Approach of Action-Research type that prioritizes the development and analysis of the process along with the "meaning" that people give to things and your life than actually the product itself. The data collected through questionnaires at the end of the course signal impressions (positive and constructive criticism) we received and the meanings experienced teacher students (testimonials, chats, discussion forums, projects) in the courses offered. The experience lived in these three courses: Virtual Learning Environment (60 hours); Tutoring in distance education (60 hours) and Teaching Materials in Distance Education (60 hours), from its conception to its actual conclusion, make us think that we are on the right way and by TDIC, new horizons may open up to the institution in short- and medium-term.
\end{abstract}

Keywords: Teacher training. Distance education. Methodology and teaching strategies. Information and communication technologies. Virtual learning environment.

\footnotetext{
${ }^{1}$ Doutor em Educação pela Universidade de São Paulo - USP/SP. Professor Colaborador da Universidade Estadual de Londrina. NEAD/UEL. E-mail: oscarfujita@outlook.com.

${ }^{2}$ Doutor em Ciências da Educação pela Faculdade de Motricidade Humana da Universidade Técnica de Lisboa. Professor da Universidade Estadual de Londrina (UEL). Coordenador PACC/UEL.

${ }^{3}$ Doutor em Engenharia de Sistemas e Computação pela Universidade Federal do Rio de Janeiro. Professor da Universidade Estadual de Londrina. Coordenador NEAD/UEL e UAB/UEL. Brasil.

${ }^{4}$ Doutor em Engenharia de Produção pela Universidade Federal de Santa Catarina. Professor da Universidade Estadual de Londrina (UEL). NEAD/UEL.
} 


\section{Introdução}

Para melhor compreendermos como se deu o processo pioneiro de formação de professores na modalidade a distância da Universidade Estadual de Londrina (UEL-PR), ocorrido no período de agosto a dezembro de 2014, faz-se necessário, realizar uma breve retrospectiva histórica da instituição e das parcerias realizadas ao longo destes anos e que culminaram, após exaustivos esforços e um meticuloso planejamento, no oferecimento de três cursos na modalidade EaD (Educação a Distância): Ambiente Virtual de Aprendizagem, Tutoria em EaD e Material Didático em EaD, em atendimento Chamada UAB No 01/2013 (COORDENAÇÃO DE APERFEIÇOAMENTO DE PESSOAL DE NÍVEL SUPERIOR, 2013).

A criação da Universidade Estadual de Londrina (UEL) ocorreu por meio da autorização no âmbito do Sistema Estadual - Lei ${ }^{0}$ 6.034, de 06/11/69 (publicada no DOE/PR n ${ }^{\circ} 209$, p. 1 e 2, de 10/11/69). O Decreto $n^{\circ} 18.110$, de 28/01/70 (BRASIL, 1970), publicado no DOE/PR n ${ }^{\circ} 275$, p. 1 e 2, de 30/01/70, cria primeiramente a UEL sob a forma de Fundação, a partir da junção de cinco Faculdades de Londrina - Faculdades Estaduais de Filosofia, Ciências e Letras de Londrina, de Direito; de Odontologia; de Medicina, de Ciências Econômicas e Contábeis (Ciências Econômicas e Administração). Iniciou com 13 cursos de graduação: História, Geografia, Letras (Anglo-Portuguesas e Franco-Portuguesas), Pedagogia, Ciências ( $\left.1^{\circ} \mathrm{Grau}\right)$, Direito, Odontologia, Medicina, Farmácia e Bioquímica, Ciências Biomédicas, Ciências Econômicas e Administração.

A Pós-Graduação também teve seu início na década de 1970. Em 1987 foi implantado o ensino gratuito nível Graduação, sendo transformado em Autarquia pela Lei Estadual $n^{\circ}$ 9.663, de 16/07/91, publicada no Diário Oficial n ${ }^{\circ} 3.555$, de 16/07/91. Em 2005, a UEL adotou o sistema de cotas para estudantes afrodescendentes e oriundos de escolas públicas em seu vestibular, e, desde 2010, utiliza os resultados do ENEM para preenchimento das vagas remanescentes.

\section{O NEAD-UEL (Núcleo de Educação a Distância)}

Desde a segunda metade da década de 1970 até 2001, a UEL participou de diversos programas nacionais relacionados à Educação Continuada e a Distância, como: PADES - Programa de Apoio ao Desenvolvimento do Ensino Superior, TIPS Módulos para a formação de docentes do ensino superior na área de saúde, BRASILEAD - Consórcio Interuniversitário, além de outras iniciativas internas provenientes dos diversos Centros de Estudos. Em 2002, o CEPE deliberou que a UEL não ofereceria cursos de graduação e pós-graduação Stricto Sensu a distância. Tal diretriz foi modificada pela Resolução CU 0154/2008 e, posteriormente, o CEPE, por meio da Resolução 0003/2009 regulamentou a oferta de atividades acadêmicas de forma semipresencial. O retorno efetivo da UEL à EaD deu-se pela criação do Núcleo de Educação a Distância - NEAD, mediante a Resolução CA/CU 0069/2009 e do Regimento do NEAD. Com a criação do NEAD-UEL, vinculado à Reitoria, houve o estabelecimento formal do lócus capaz de articular as ações institucionais relacionadas com a $\mathrm{EaD}$, com os objetivos de:

- oportunizar a democratização do conhecimento, por meio do acesso ao saber acadêmico;

- estimular e apoiar ações de Educação a Distância;

- incentivar o uso de ferramentas e Tecnologias Digitais de Informação e Comunicação (TDIC), visando a melhoria da qualidade do ensino, da pesquisa e da extensão;

- propor política de estímulo à produção científica e buscar parcerias e recursos para o desenvolvimento de Educação a Distância.

Juntamente com o NEAD está o LABTED (Laboratório de Tecnologias Educacionais) 
que articulam as principais ações institucionais relacionadas a esta modalidade de ensino e seus aparatos, visando atender as proposta de demanda referente às necessidades formativas dos profissionais da comunidade interna da UEL, assim como a comunidade externa.

De maio até novembro de 2009, a UEL promoveu um conjunto de capacitações presenciais em EAD como resultado dos esforços conjuntos da Pró-Reitoria de Recursos Humanos (PRORH/UEL) e da Escola de Governo do Paraná. Desta iniciativa, 9 cursos foram realizados: Moodle - sistema de gerenciamento de cursos; Planejamento, Design, Produção e Avaliação de Programas de Educação On Line; Gestão do E-learning; Produção e Avaliação de material didático; Educação a distância: entre leis e perspectivas; Vídeo na Rede; Elaboração de projetos em EaD; Direitos Autorais e Capacitação de Instrutores totalizando mais de 140 horas de capacitação em temas da EaD.

\section{A Universidade aberta do Brasil (UAB) e o estabelecimento de parcerias}

No campo de novas tecnologias educacionais, a Capes vem, há algum tempo, investindo fortemente na pesquisa e no aprimoramento de metodologias heurísticas e no desenvolvimento de estratégias metodológicas que atendam a esta demanda. Dentre essas ações, podemos citar o PAPED - Programa de Apoio à Pesquisa em Educação a Distância, articulação realizada entre a Capes com a extinta SEED/MEC, que prevaleceu de 1999 a 2005.

A UAB propriamente dita foi instituída pelo Decreto 5.800, de junho de 2006, tendo como objetivo o desenvolvimento da modalidade EaD. Sua operacionalização ficou a cargo da Diretoria de Educação a Distância (DED) da Capes e transferida posteriormente para a Secretaria de Educação a Distância (SEED/MEC) pela Portaria MEC 318, de 2 de abril de 2009 (BRASIL, 2009). Esta portaria tem como objetivo integrar todas as IES que ofereciam cursos de nível superior, voltadas principalmente para camadas da população com possuem dificuldades de acesso à formação universitária, através da modalidade de Educação a Distância. Seus eixos principais se baseiam: (a) na expansão pública da educação superior, (b) no aperfeiçoamento de processos de gestão das IES e (c) no financiamento dos processos de implantação, execução e formação em recursos humanos em EaD (Educação Superior).

Como forma articular e avançar nas questões ligadas a EaD, o importante Edital Capes 15/2010 teve como intenção fomentar ao uso das TDIC nas IPES (Instituições Públicas de Ensino Superior) pertencentes ao Sistema da UAB, cujo objeto era a integração e a convergência entre Educação Presencial ea Distância, por meio do uso disseminado das TDIC, em especial no universo educacional dos cursos de graduação convencionais.

Segundo Kenski (2015, p. 68), diferentemente como pensam alguns,

\begin{abstract}
O ambiente educacional virtual não suprime o espaço educacional presencial. Ao contrário, ele o amplia. Os projetos de educação permanente, as diversas instituições e os vários cursos podem ser oferecidos para todos os níveis de ensino e para todas as idades, a internacionalização do ensino - através das redes - criam novas dimensões para o acesso à educação, novas possibilidades de comunicação e agregação, novas oportunidades para o avanço na ação e na formação do cidadão que habita os múltiplos espaços das escolas - e das suas múltiplas linguagens.
\end{abstract}

Levy (1999, p. 44) acrescenta que "o virtual não se opõe ao real, mas se manifesta como uma potência”. Araujo e Marquesi (2009, p. 360) reforçam: "na verdade, as situações do presencial e a do virtual promovem a aprendizagem de maneira diferenciada e podem complementar-se".

Desta forma, o presente edital, tinha como pretensão favorecer a institucionalização de metodologias e práticas de ensino e aprendizagem inovadoras que, com o uso das TDIC, pudessem auxiliar na criação e/ ou incrementar uma cultura acadêmica, cujos recursos tecnológicos avançados pudessem ser um instrumento útil para a otimização da gestão universitária. 
O PACC - Programa de Aperfeiçoamento e Capacitação Continuada foi criado para dar prosseguimento a estas ações. Esta articulação com a Capes foi estabelecida pelo Decreto 29.741, de 11 de julho de 1951 (BRASIL, 1951), tendo como essência assegurar a existência de pessoal especializado em quantidade e qualidade suficientes para atender às necessidades dos empreendimentos públicos e privados, visando o desenvolvimento do País e as Instituições Públicas de Ensino Superior (IPES) integrantes do Sistema UAB. Tem como principais objetivos:

- buscar fomentar e validar novas formas de ensinar e aprender no âmbito de uma Educação de qualidade;

- criar espaço de formação profissional que contribuam para a expansão e o reconhecimento da $\mathrm{EaD}$ na sociedade, sobretudo, em sua dimensão pública ligada a democratização e acesso ao Ensino Superior;

- implantar e implementar cursos de curta duração para formação continuada de: professores conteudistas, professores formadores, tutores presenciais, tutores a distância coordenadores de pólos, equipes de apoio interdisciplinar (administrativos, secretárias, suporte técnico, web designer, editores de imagens, revisor entre outros) em EaD.

O PACC tem a incumbência de selecionar termos de referência para a oferta de cursos de especialização, extensão ou aperfeiçoamento, na modalidade presencial, semipresencial (blended learning) ou a distância, cujos conteúdos e metodologias proporcionem conhecimentos efetivos à qualificação dos profissionais dedicados aos projetos e cursos deste órgão. Podem participar do programa UAB todas as IPES: Universidades Públicas (federais, estaduais ou municipais), Institutos Federais de Educação e Institutos de Ciência e Tecnologia (UTFPR, IFPR). Estas IPES são responsáveis pela criação de seus respectivos PPCs - Projetos Pedagógicos de Cursos e pela boa qualidade de seus cursos, tendo como base os Referenciais de Qualidade ${ }^{5}$ para a Educação Superior a Distância - SEED/MEC.

Todas as iniciativas atuais foram ampliadas com tecnologias de conferência web, possibilitando a gravação e retransmissão de aulas, palestras e vídeos para os polos, entre os campi das IES e outras fontes. As atividades didático-pedagógicas virtuais e a transmissão-reprodução assíncrona de eventos têm a pretensão de se constituir numa autêntica "UAB da Nuvem". O alcance das ações para materializar a "UAB da Nuvem" implica na ampliação do financiamento realizado pela Capes, no âmbito de programas (PACC e PAPED), além de novos editais de fomento ao uso de TDIC, com vistas a tornar acessível e consolidar em todas as IES/Polos da UAB os conteúdos abertos na internet, fator indispensável à disseminação da cultura desta "nova" modalidade de ensino e aprendizagem $(\mathrm{EaD})$, com qualidade adequada esperada.

Neste contexto, é importante ressaltar o fenômeno de expansão da oferta dos chamados MOOCs (Massive Online Open Courses ou Cursos Abertos Massivos pela Internet), analisado por Mota e Inamorato (2012) e os investimentos, hoje em escala global, em laboratórios de desenvolvimento de novas tecnologias para estudantes do ensino médio ${ }^{6}$. Sobre esses aspectos, todos os agentes integrantes do Sistema UAB deverão, em caráter obrigatório e de urgência, se debruçar nos próximos anos.

Diante destas proposituras, a UEL, sensível às transformações educacionais presentes, credenciou-

${ }^{5}$ Referencial de Qualidade - Elaborado pela SEED/MEC em complemento a determinação da LDB de dezembro de 2005, do decreto 5.773 de junho de 2006 e das Portarias Normativas 1 e 2 de janeiro de 2007. (BRASIL, 2007).

${ }^{6}$ Pesquisador brasileiro Paulo Blikstein: ganhou prêmio nos EUA por suas pesquisas voltadas para o Ensino Médio (BLIKSTEIN, 2012). 
se em 2010 ingressando definitivamente em 2011. Ofertou inicialmente pelo Programa Nacional de Formação de Professores o curso de Pedagogia na modalidade a distância para um público específico, em atendimento ao CNE e CEE, o que aconteceria no último trimestre de 2011 e que teve seu início em dezembro de 2011 com 2.472 estudantes distribuídos nos polos UAB de Colombo, Cerro Azul, Paranaguá e Palmeira com término previsto para março de 2013.

A UEL, por ser ainda uma instituição neófita no sistema da UAB, pois foi a última IES Estadual ativa do PR a entrar no sistema (as outras são: UEM, UEPG, UNICENTRO), ainda não tinha tido a oportunidade de participar de nenhum curso de capacitação e formação continuada, sob a sua supervisão. Desta forma, a participação nesta referida Chamada UAB N ${ }^{\circ}$ 01/2013, se justificou plenamente como oportunidade primeira na capacitação e formação de educadores no tocante aos critérios de seleção das metodologias e do desenvolvimento das estratégias didático-pedagógicas voltadas, exclusivamente, à Educação a Distância (COORDENAÇÃO DE APERFEIÇOAMENTO DE PESSOAL DE NÍVEL SUPERIOR, 2013).

\section{O Oferecimento de Cursos e a Metodologia Utilizada}

Em atendimento à Chamada UAB $\mathrm{N}^{\circ}$ 01/2013, foi oferecido aos docentes (Graduação e Pós-Graduação), funcionários e discentes da Universidade Estadual de Londrina (UEL-PR) três cursos de extensão universitária na modalidade a distância:

- Ambiente Virtual de Aprendizagem (60 horas);

- Tutoria em EaD (30 horas); e

- Material Didático em EaD (60 horas).

Os cursos foram realizados no período de agosto a dezembro de 2014 e contou com a participação total de 184 cursistas, sendo $37 \%$ do sexo masculino e $63 \%$ do sexo feminino. No tocante as atividades profissionais dos cursistas, tivemos 20\% discentes da Graduação, $13 \%$ discentes da Pós-Graduação, 29\% docentes, 4\% do PDE (Programa de Desenvolvimento Educacional) e 35\% Técnicos Administrativos.

O modelo pedagógico empregado nos cursos foi o blended learning (cursos híbridos), isto é, encontros virtuais intercalados com encontros presenciais. Esta opção adotada pela coordenação do curso teve sua base calcada em pressupostos teóricos e da experiência de seus precursores. Almeida (2003) reforça a escolha acertada e esclarece que as interações presenciais dentro dos cursos a distância, somente têm aspectos positivos, pois após os encontros presenciais os alunos podem

[...] continuar o diálogo de qualquer outro espaço físico que permita o acesso à Internet e em qualquer momento que se tenha disponível. Rompe-se assim com a limitação espaço-temporal da aula, o que possibilita a abertura da sala de aula e dos espaços pedagógicos para o mundo, bem como a integração das organizações educacionais com os demais setores da atividade humana que também constituem espaços produtores de conhecimento. (ALMEIDA, 2003, p. 208)

A prática educacional e a eficácia dos resultados dos cursos nesta modalidade de ensino têm mostrado que, independente do seu objetivo, sempre que possível evidentemente, é recomendável ter momentos presenciais. O "olho no olho", o contato físico e pessoal faz parte do ser humano, pois por natureza, somos seres sociáveis.

Para Lima7 (1998, p. 12), essas relações e o ambiente de sala de aula (seja ela física ou virtual) estão tomando novos rumos e dimensões. $\mathrm{Na}$ sociedade da informação, segundo o mesmo autor, o conhecimento extrapola os limites das escolas e passa a contar com os meios de comunicação

\footnotetext{
${ }^{7}$ McLuhan - Recomendamos a leitura de Lima: “Mutações em educação segundo McLuhan”, 1998.
} 
de massa (internet e chats, videoconferência, teleconferência) - como extensão do ser humano e a Educação começa a ser vista como um processo de comunicação e de permuta. A competição não é mais a mola propulsora do sucesso e sim a colaboração, a união das diferenças, a qual se dá por meio do que McLuhan chama de discussões em grupo, que compreende um processo coletivo de engajamento, integralidade e diversificação -

\section{Aprendizagem Colaborativa.}

Calcados nos pressupostos acima apresentados, foram oferecidos dois encontros presenciais ao longo dos cursos, que contabilizaram 10 horas da carga horária total de seus respectivos cursos:

- $1^{\circ}$ encontro: início do curso. Foi realizada uma explanação pelos Coordenadores e alguns esclarecimentos sobre: $\mathrm{O}$ que é o PACC/UEL? Quais metodologias seriam utilizadas nos cursos PACC e uma apresentação sobre o NEAD/UEL e suas ações. Posteriormente foi realizada uma palestra ministrada pelo coordenador da UAB/UEL intitulada "Como estudar a distância: técnicas analógicas e digitais" com o objetivo de sensibilizar a comunidade interna da instituição e os cursistas no tocante as novas formas de ensinar e aprender e consecutivamente a estudar diante dos novos desafios que porventura poderiam aparecer no transcorrer do curso.

- $2^{\circ}$ encontro: foi realizado outro encontro no final do curso, com esclarecimentos gerais e avaliação final.

\section{Delineamento Metodológico e Análise dos Dados}

O delineamento metodológico foi desenvolvido segundo a Abordagem Qualitativa. De acordo com Bogdan e Biklen (2010 apud LUDKE; ANDRÉ, 2013, p. 11), cinco características básicas configuram este tipo de abordagem:
1. "A pesquisa qualitativa tem o ambiente natural como sua fonte direta de dados e o pesquisador como seu principal instrumento". Os autores tiveram participação direta nos projetos oferecidos (concepção, planejamento, desenvolvimento, execução, avaliação) e por um período de cinco meses realizaram a coleta de dados;

2. "Os dados coletados são predominantemente descritivos". Os dados são apresentados em sua maioria de maneira descritiva, com depoimentos e comentários dos cursistas individualmente. As atividades desenvolvidas e seus projetos foram documentadas no próprio AVA (projetos e vídeos), observações do cotidiano, percepções dos autores e questionários respondidos durante e após a conclusão do curso;

3. "A preocupação com o processo é muito maior do que com o produto". Esta preocupação esteve presente durante todo o processo. $\mathrm{O}$ aperfeiçoamento da metodologia e das estratégias didáticas aplicadas a EaD utilizadas durante os cursos foram focos e tiveram atenção especial dos autores;

4. “O 'significado' que as pessoas dão às coisas e à sua vida são focos de atenção especial pelo pesquisador". Todas as impressões quanto ao "significado" que os cursistas deram ao curso e de forma indireta nas ações relacionadas à sua vida, foi possível ser coletado por meio dos questionários de avaliação aplicados ao final do curso: expectativas que tinham do curso, dificuldades individuais, críticas construtivas, elogios, sugestões de melhorias, novos cursos que gostariam de fazer,... Esses aspectos foram analisados pelos autores, num processo de retroavaliação, de tentativas de acertos e erros, de assimilação e de preocupação com os novos formatos que serão adotados nas próximas versões dos cursos;

5. "A análise dos dados tende a seguir um processo indutivo. Os coordenadores/autores não se preocuparam em buscar evidências que comprovassem hipóteses definidas antes do 
início dos estudos". Os aspectos quanto ao desenvolvimento do processo (estabelecimento de parcerias e suas articulações, definição dos cursos oferecidos, contratação de profissionais, atendimento ao edital de convocação dos cursistas, inscrição, definição da metodologia e de suas estratégias pedagógicas e avaliação/ aproveitamento dos cursistas) foram etapas desenvolvidas sempre com o "olhar" criterioso e os resultados analisados com intenções futuras.

Entre as diversas variantes da Pesquisa Qualitativa, consideramos a presente do tipo Pesquisa-Ação. Segundo Barbier (2008, p. 37) a pesquisa-ação é "'[...] uma ação em nível realista, sempre acompanhada de uma reflexão autocrítica objetiva e de uma avaliação dos resultados".

Os autores/pesquisadores, mesmo tendo posse de dados estatísticos, sempre deram ênfase as impressões manifestadas pelos cursistas por meio dos e-mails, dos comentários emitidos no próprio AVA e também por meio das respostas sinceras emitidas nos questionários da Avaliação Final. Salientamos que, a reunião de todos os aspectos acima citados foi marcante e significativa para a análise do processo como um todo.

\section{Resultados Obtidos}

Conforme já mencionado acima, as impressões e o significado que os cursistas tiveram sobre os cursos foram mais significativos e marcantes - para nós enquanto pesquisadores e coordenadores - que os dados estatísticos obtidos. Entretanto, apresentamos os dados numéricos abaixo que também comprovam e reforçam as impressões obtidas de forma indutiva, como poderão verificar a seguir.

Quanto à faixa etária dos participantes, as estatísticas mostraram que $7 \%$ eram cursistas com até 24 anos, 29\% de cursistas entre 25 a 34 anos, $36 \%$ de cursistas entre 35 a 55 anos, $20 \%$ de cursistas de 45 a 54 anos e $7 \%$ com cursistas com mais de 54 anos (Figura 1).

Figura 1 - Faixa Etária por participante

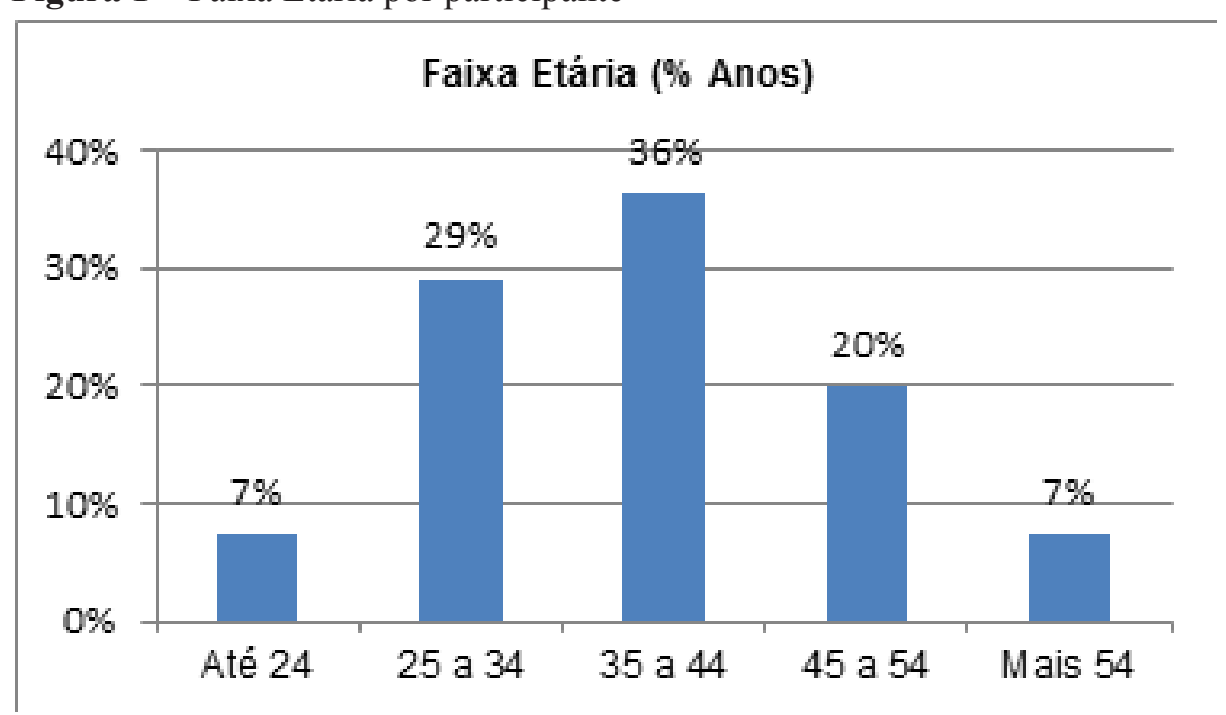

Fonte: NEAD/UEL (2015).

A média aqui apresentada, e com destaque para a faixa de 35 a 44 anos, não se diferencia da média nacional no tocante aos cursos de aperfeiçoamento e pós-graduação (FUJTTA, 2010, p. 158). Os números comprovam definitivamente que a EaDéa modalidade de ensino e aprendizagem preferida do aprendente 
adulto (andragogia ${ }^{8}$ ) e neste caso mais específico, totalmente influenciado pelo perfil requisitado nos cursos. No entanto, ainda segundo o próprio autor, esta média vem baixando ano a ano, seja pelo maior contato das pessoas com as Tecnologias Digitais de Informação e Comunicação (TDIC), seja pela disseminação da filosofia de se educar a distância, pelo conhecimento mais massificado da metodologia, das estratégias didáticas e Ambientes Virtuais de Aprendizagem (AVA) que envolvem a EaD.

Quanto à adoção do modelo pedagógico empregado nos cursos blended learning, os cursistas se mostraram favoráveis ao este tipo de modelo e a aula presencial ( 2 encontros), pois $31 \%$ consideraram ótimo, $42 \%$ consideram boa, $16 \%$ regular, $4 \%$ péssima e 7\% não responderam (Figura 2).

Figura 2 - Avaliação quanto à aula presencial

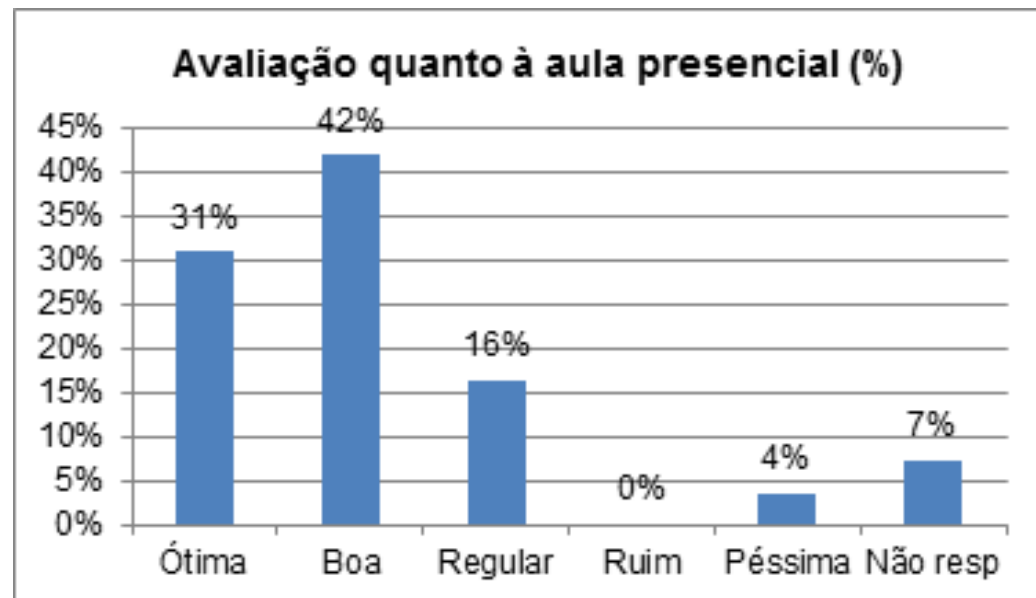

Fonte: NEAD/UEL (2015).

Quanto a avaliação do material leituras complementares,...) os cursistas didático oferecido (e-books, vídeos, links, responderam: 56\% ótimo, 35\% bom e 9\% bibliografias adicionais, recomendação de regular (Figura 3).

Figura 3 - Avaliação do material didático

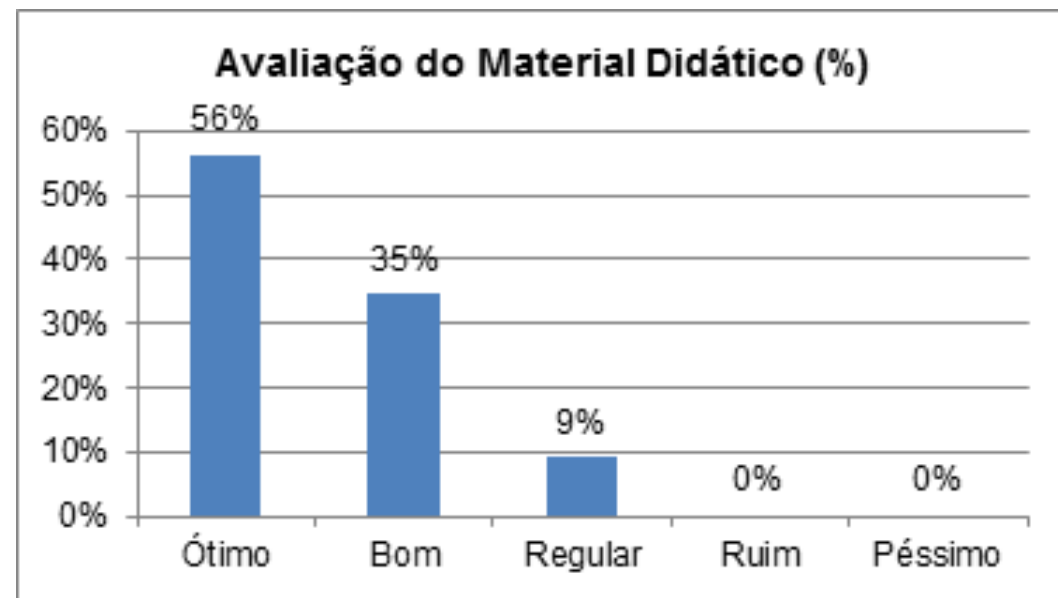

Fonte: NEAD/UEL (2015).

${ }^{8}$ Andragogia - Andrós = adulto. Agogé = conduzir, educar, guiar. Arte de ensinar adultos. 
Os números acima somente traduzem, por meio de seu depoimento, as impressões da cursista CNN

Eu trabalho com material didático e posso afirmar que o conteúdo estava muito bom. Vi poucos erros nos materiais (do curso e dos colegas de curso - nos projetos). Todos sempre com crédito da imagem, referência e bem didáticos. Gostei muito do curso [...]. Não estava longo para um curso de $60 \mathrm{~h}$ e nem curto. Dava o conteúdo que seria cobrado na avaliação e para a prática. Referencias para quem quisesse estudar mais. (Cursista CNN)

Quanto à Metodologia de Ensino e Aprendizagem adotado nos cursos - no momento da concepção do Projeto Político Pedagógico -, obteve uma boa aceitação por parte dos cursistas, a saber (Figura 4):

Figura 4 - Metodologia de ensino e aprendizagem

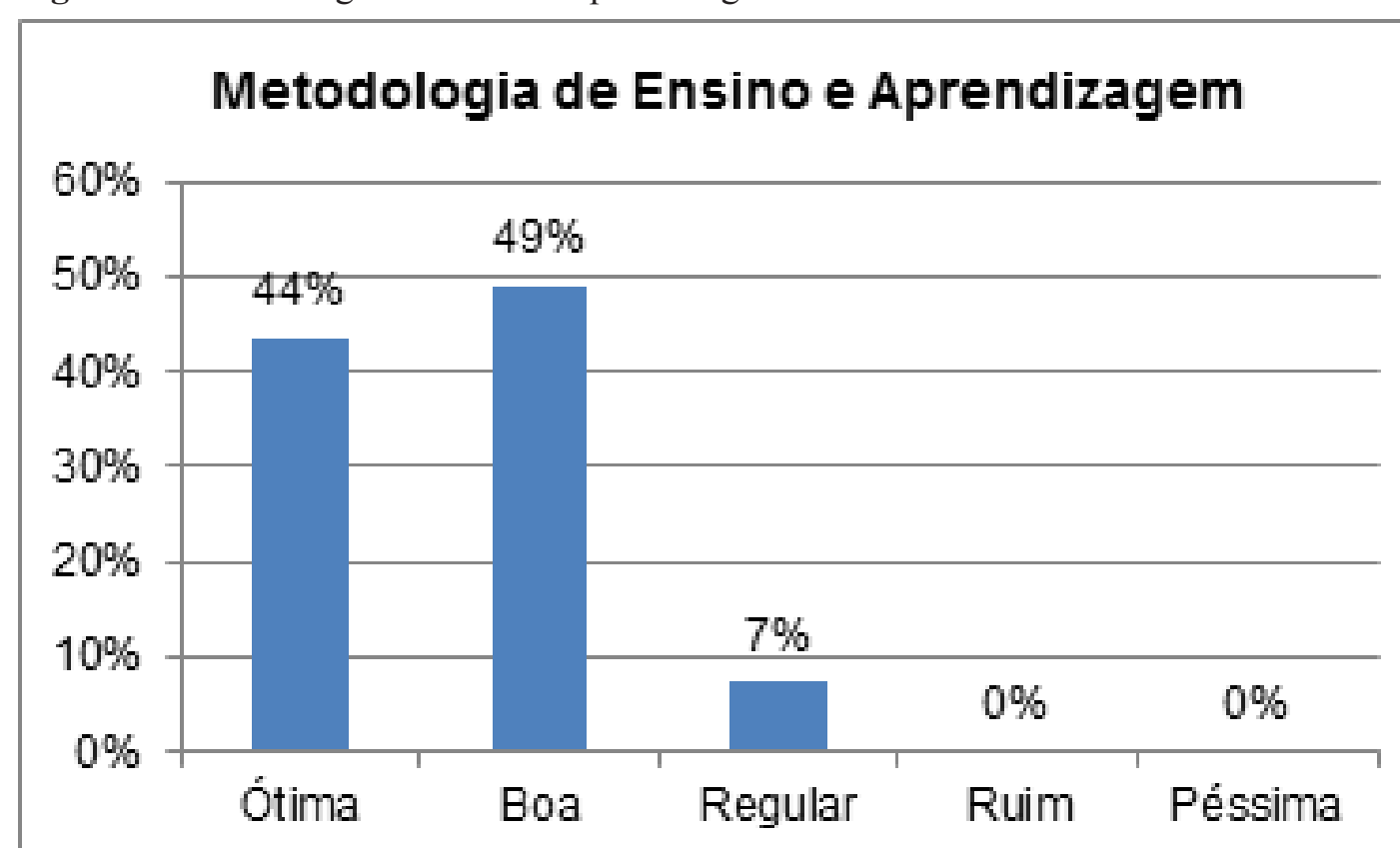

Fonte: NEAD/UEL (2015).

“É um ótimo curso devido à metodologia e à plataforma usadas. Isso permite que os alunos aprendam na medida de seus interesses. Por causa disso, o conteúdo fixa mais na mente, sem aquela "pressão" habitual que a gente tem no ensino presencial. O aprendizado é sólido". (Cursista SMB)

Os resultados abaixo evidenciam que grande parte dos percentuais positivos obtidos está relacionada ao desempenho dos profissionais ligados a este curso e que principalmente tiveram um contato mais direto com os cursistas: professores, tutores e equipe de apoio. No entanto, compartilhamos os créditos com todos os profissionais que de forma direta ou indireta atuaram e também fizeram parte deste processo educacional - uma equipe multidisciplinar, multifacetada e com funções pré-definidas: coordenadores, professores (formador e conteudista), tutores, secretarias, suporte técnico, web designer, editores de imagens e revisor. 
Figura 5 - Desempenho dos professores

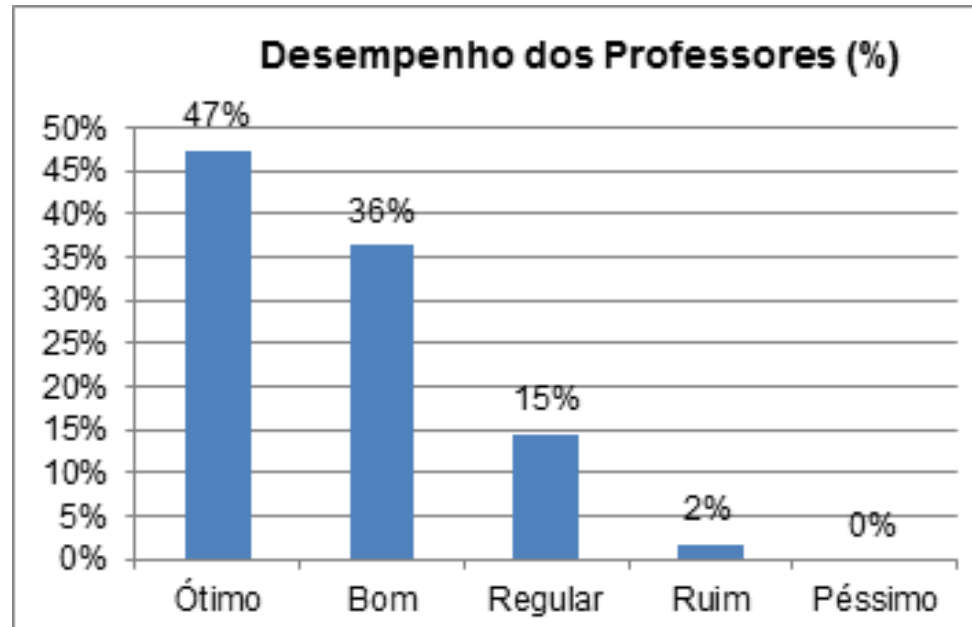

Fonte: NEAD/UEL (2015).

"Obrigada a todos que fizeram parte disso tudo, desde técnicos de estúdio, pessoal do design, tutores, professores, coordenadores e diretores dos órgãos envolvidos, e ao Professor, pela paciência e dedicação sempre renovada, pelo bom humor e pelos conhecimentos partilhados". (Cursista CGG)

Os Tutores - nosso próximo item de análise - possuem papel fundamental no processo educacional EaD. Dentre suas atividades, destacamos: participação ativa na prática pedagógica, auxílio sistemático e colaborativo junto ao cursista em questões administrativas, tecnológicas, acompanhando todo o seu processo de aprendizagem e garantindo segurança e bemestar. Contribui humanizando a relação professor/ tutor-computador-cursista e vice-versa e ainda, auxiliam o cursista no desenvolvimento e busca de sua autonomia intelectual. Costumeiramente, reforçamos que bons tutores ajudam a diminuir a distância transacional ${ }^{9}$.

Figura 6 - Desempenho dos tutores

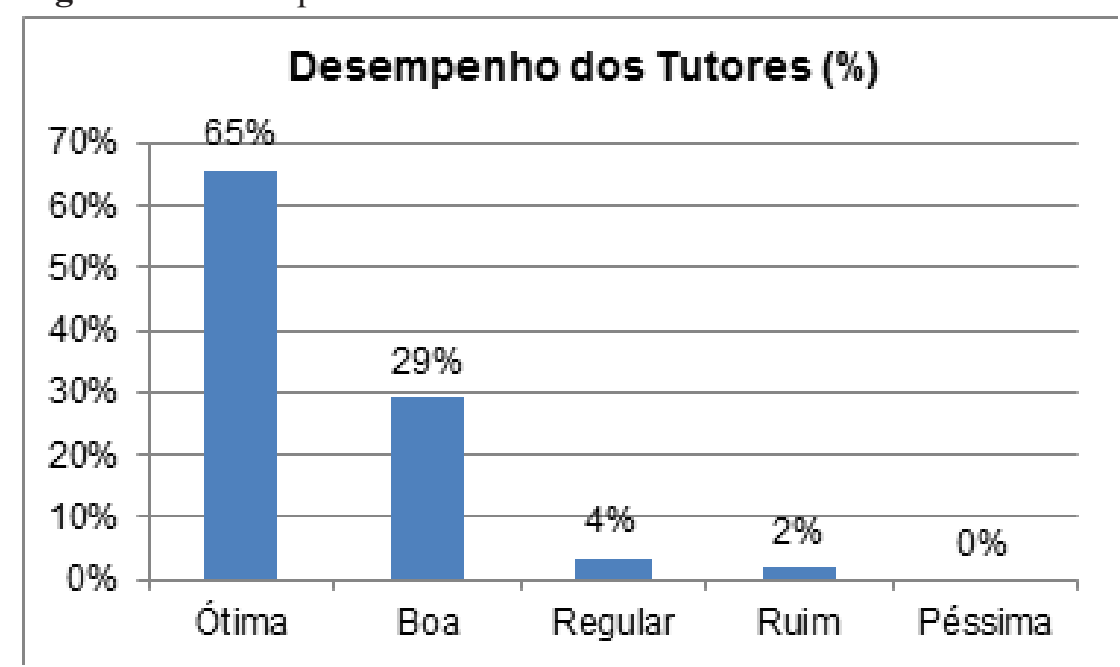

Fonte: NEAD/UEL (2015).

${ }^{9}$ Distância Transacional: recomendamos a leitura de Paul Bouchard (2001): “Autonomia e distância transacional na formação a distância”. 
Com o passar do tempo e com as conversas com a Tutora, tudo foi ficando mais fácil. Reconheço que esgotei a paciência da mesma, mas valeu a pena porque vi um mundo novo se abrindo na minha frente, novas possibilidades, novos conceitos, novos desafios... E a experiência se tornou positiva $e$ prazerosa, conforme as conversas com os membros do grupo. Mas confesso que o que aprendi com o curso, só consegui entender/aprender de tanto fazer, errar e tentar de novo. (Cursista DLMLP)

Com esta ideia, observe-se o relato que comenta sobre a tutoria recebida e o papel da secretaria:"Primeiramente a minha tutora que foi extremamente atenciosa e não me deixou com dúvidas em momento algum. As pessoas responsáveis na preparação dos materiais e a secretaria que foram muito pontuais em seu papel! Obrigado”. (Cursista MHS)
Outro aspecto positivo e marcante na pesquisa realizada sobre os tutores foi a avaliação realizada sobre o prazo de retorno dos tutores ao chamamento dos cursistas. Quanto menor for o prazo de resposta a solicitação dos cursistas, neste caso específico (65\% ótima $+29 \%$ boa $=94 \%)-$ Figura 7, maior será a sensação de acompanhamento e de apoio sentida pelo cursista. Nossas experiências anteriores têm demonstrado que grande parte do índice relacionado à desistência dos cursos nesta modalidade de ensino tem sido atribuída, entre outros casos, a falta de acompanhamentos mais sistematizados e particularizados ao cursista.

Figura 7 - Prazo de retorno dos Tutores

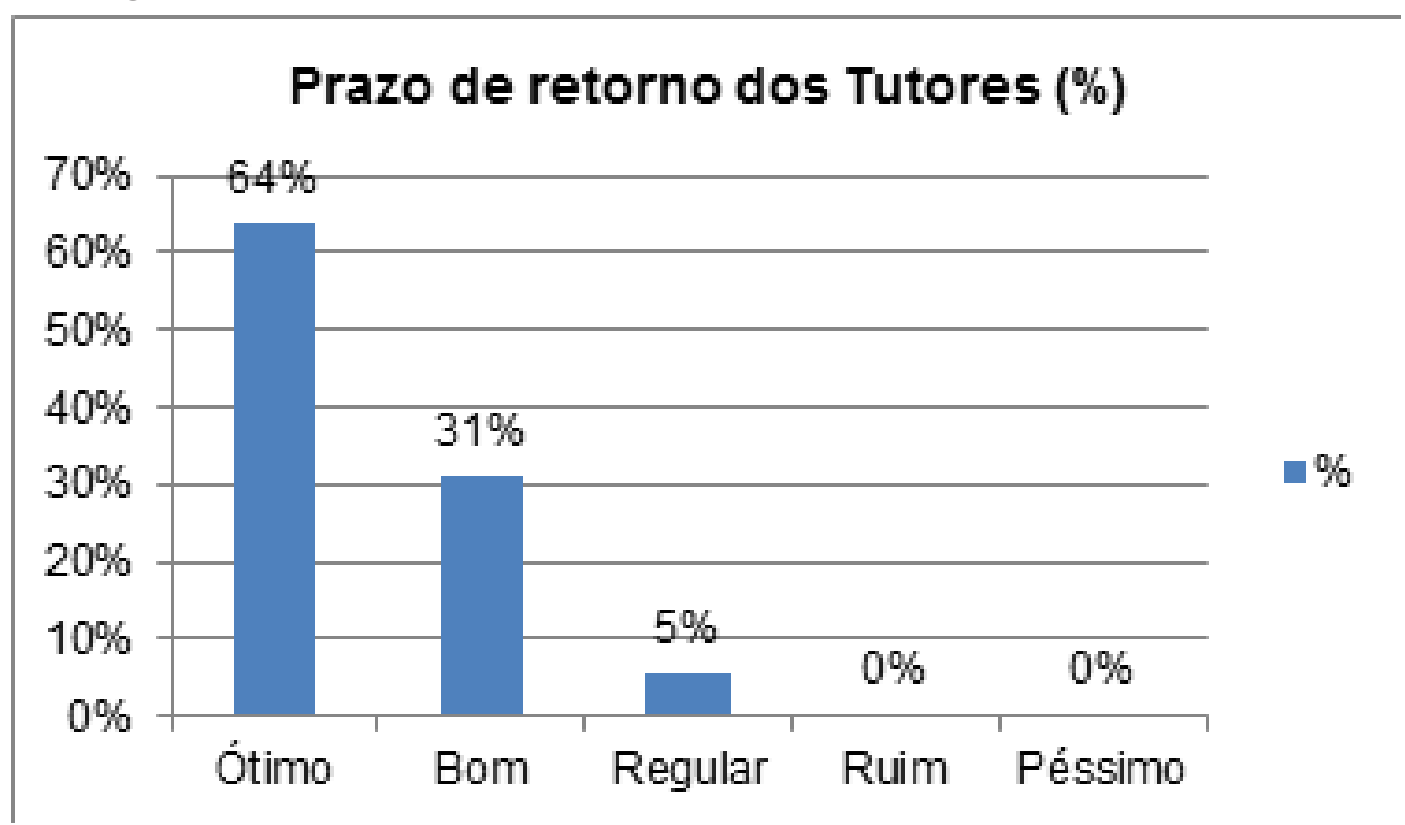

Fonte: NEAD/UEL (2015).

"A pronta resposta da tutora às minhas dúvidas tanto de conteúdo como na plataforma. A sensibilidade, gentileza e pronto atendimento da secretaria do PACC”. (Cursista $\mathrm{KJ})$

"Só posso agradecer toda a ajuda da tutora por ter compreendido minhas dificuldades com a plataforma Moodle e com relação aos meus problemas com falta de horário. Me esforcei e fiz o que pude, mas sem a ajuda da equipe, talvez eu não teria conseguido terminar o curso". (Cursista APLBP) 
Figura 8 - Desempenho da Equipe de Apoio

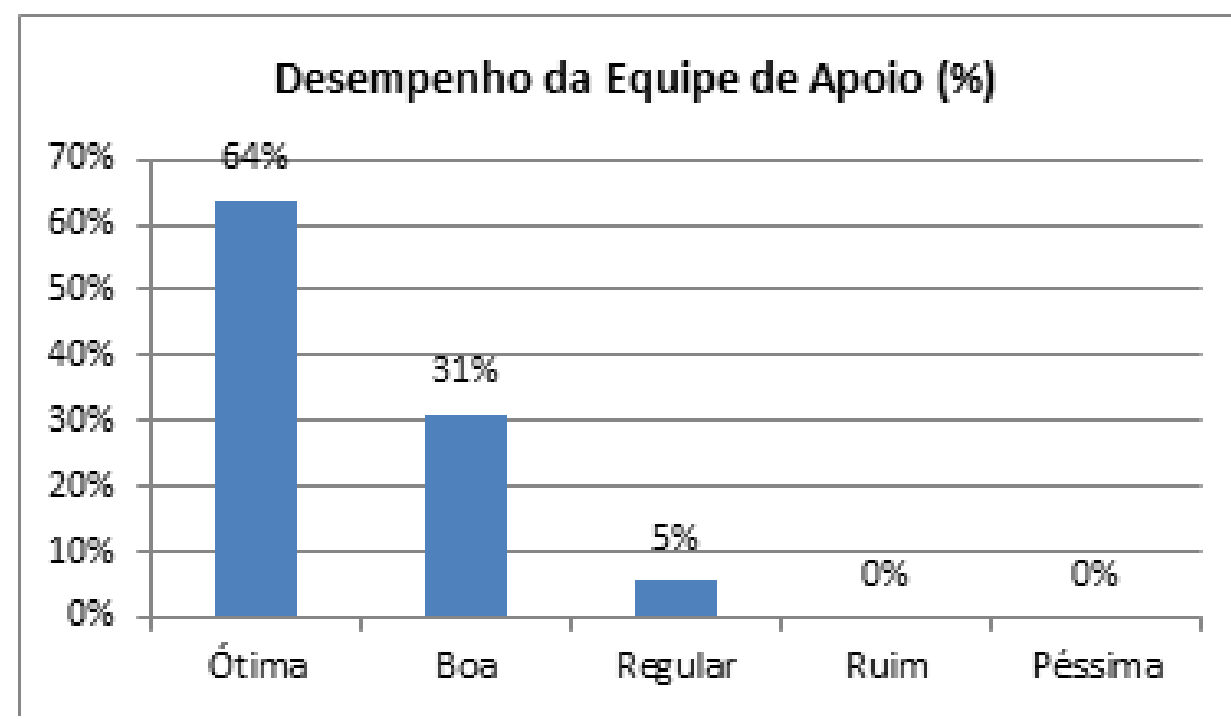

Fonte: NEAD/UEL (2015).

\begin{abstract}
Assim, o que fica para mim é a experiência adquirida e a certeza que tentarei ser melhor nas próximas empreitadas, pois é errando que se aprende. Gostaria de deixar aqui meu agradecimento a toda equipe do curso, pela paciência, carinho e disponibilidade em nos ajudar quando fosse preciso. $O$ curso foi realmente maravilhoso. (Cursista AML)
\end{abstract}

Os coordenadores foram muito importantes para manter a organização na equipe. A Tutora sempre disposta a ajudar. Foi muito bom participar do curso, aprendi muito. Acho que poderia ter me dedicado mais, participado dos fóruns, ter sido mais colaborativa no curso. Agradeço muito aos Professores e aos Tutores, pelo belo trabalho. (Cursista LSGG)

Estamos convictos de que a composição da equipe interdisciplinar nos trabalhos que envolvem o ensino e a aprendizagem a distância, está intimamente relacionada à boa seleção/ contratação destes profissionais. A primeira vista, parecem ser redundantes estas colocações, mas se fazem necessárias devido a sua especificidade. A organização das estratégias, a forma como estas estratégias didáticas são conduzidas (professor), a maneira como nos comunicamos com os cursistas (tutores) e os problemas técnicos que porventura ocorrem e que devem ser rapidamente solucionados (equipe de apoio) entre outras, isto é, tudo que está relacionado ao curso, à distância se torna mais complexo e pode assumir graus e dimensões muito maiores que se acontecessem na modalidade presencial. Evidentemente que, não queremos aqui fazer comparações entre o virtual e o presencial, mas apenas como forma de relacionar evidências.

\section{O Sistema de Avaliação}

Antecedentes históricos da Educação têm nos mostrado que um dos grandes entraves e considerado um aspecto muito discutível, tem sido o sistema de avaliação adotados nas disciplinas e em seus respectivos cursos, seja na modalidade presencial ou a distância.

Neste curso especificamente, foram realizados diversas estratégias didáticas visando oferecer ao aluno uma avaliação formativa e diagnóstica ${ }^{10}$ (AZZI, 2002, p.23), atividades descritivas,

${ }^{10}$ Avaliação formativa e diagnóstica - contínua, cumulativa não no sentido de acumular resultado, mas no sentido de que o conhecimento não pode ser avaliado de maneira fragmentada; abrangente no sentido de verificar se o aluno possui uma visão macro da problemática; sistemática e finalmente flexível, no sentido de poder ser avaliada a qualquer momento, em qualquer tempo. (AZZI, 2002, grifo nosso) 
fóruns de discussão (abertos), acompanhamento sistemático dos tutores (conteúdo e dúvidas técnicas e pedagógicas), suporte técnico (via e-mail do AVA) e administrativo (documentação e acessos ao sistema). Entretanto, foi realizada apenas uma avaliação formal de final de curso em atendimento a legislação vigente. Os dados seguintes referem-se a este instrumento formal, utilizado para avaliar o desempenho dos cursista.

Figura 8 - Instrumento avaliativo

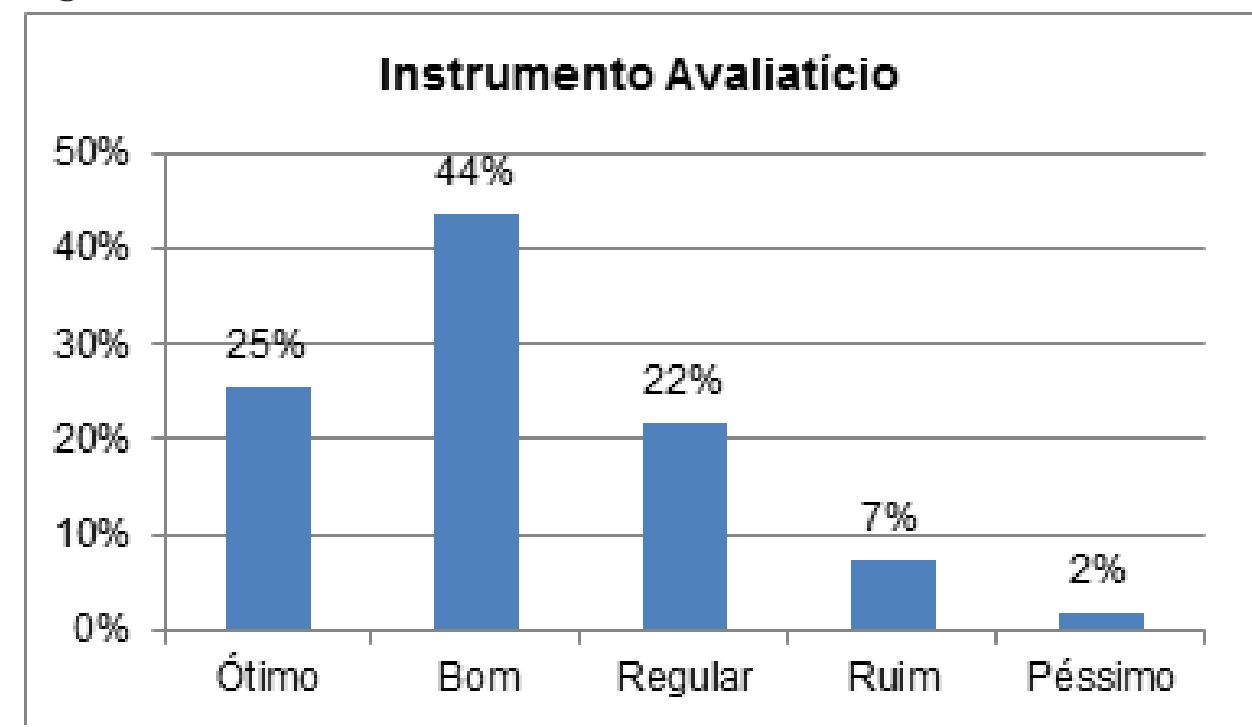

Fonte: NEAD/UEL (2015).

Sobre este tipo de avaliação os cursistas emitiram alguns depoimentos que nos fazem refletir:

"Primeiramente o aluno deveria ser avaliado como um todo e não só na prova final. Tudo deveria contar pontos: participação dos fóruns, trabalho em equipe, quanto tempo ele atuava no curso $e$ etc"; (Cursista IAR)

"O que me chamou a atenção foi a avaliação final, realizada de forma tradicional. As diversas atividades desenvolvidas já poderiam ser consideradas uma avaliação. Até poderíamos ter uma avaliação nos moldes tradicionais, mas não com o peso tão elevado"; (Cursista KMS)

"Passamos por várias avaliações no decorrer do curso, no entanto, para sermos aprovados ou não, só foi válido a avaliação final. [...] Seria avaliado todo o processo, o que é de fato legítimo em um processo de avaliação. Trata-se de processo, do contrário caímos no mesmo método presencial e tradicional”. (Cursista SMG)

Os comentários emitidos pelos cursistas nos alertam e sinalizam certo grau de insatisfação com o modelo de avaliação aplicado. Todo o processo educacional baseou-se no principio da Aprendizagem Colaborativa Virtual, defendida por Behrens (2013), Almeida (2001), Palloff e Pratt (2002), Harasim (2006) e Moran (2007). Baseado nestes princípios, diversas estratégias didáticas foram realizadas com o intuito de analisar e verificar o grau de conhecimento obtido pelos cursistas durante o processo por meio da avaliação formativa e diagnóstica. No entanto, para atender a legislação atual, que exige uma avaliação final presencial, foi considerado apenas este quesito para a emissão da nota 
final. Realizamos de certa forma, uma avaliação praticamente baseada nos moldes tradicionais.

Somos capazes de reconhecer que novas metodologias requerem novas formas de avaliação. Desta forma, a reflexão sobre os resultados e os depoimentos dos cursistas nos fará repensar sobre outras formas de valorizar e pontuar todas as atividades realizadas no processo e paralelamente o atendimento da legislação vigente.

Sabemos que estamos passando por um período de reestruturação e que a própria legislação tende a se adequar aos novos formatos com o objetivo de tornar a Educação mais eficiente, cujos resultados aparecerão num futuro bem próximo.

Ficamos felizes em participar deste processo e poder compartilhar com especialistas e profissionais ligadas a temática, nossos acertos e também, porque não dizer, os nossos erros. Estamos convictos de que estamos no caminho certo e os resultados iniciais obtidos são apenas uma amostragem de outros que virão.

\section{Considerações Finais e Perspectivas Futuras}

O oferecimento dos cursos no $2^{\circ}$ Semestre 2014 pela Universidade Estadual de Londrina (UEL-PR): Ambiente Virtual de Aprendizagem, Tutoria em EaD e Material Didático, são frutos de diversas ações realizadas ao longo de sua história e de profissionais que acreditaram que o ensino e a aprendizagem nas diversas áreas do conhecimento, não podem estar desconectadas das necessidades e demandas atuais.

As TDIC, seguindo nesta linha de pensamento, vêm ocupando cada vez mais espaço na sociedade (cotidiano das pessoas) e também, por que não dizer, nos ambientes escolares. Novas formas de acesso e de tratamento das informações, de convertêlas em conhecimento e de aprender implicam, também, em novas formas de ensinar e de aprender (educação continuada e para a vida). As TDIC na Educação ampliam nosso horizonte e fazem com que possamos sonhar com dias melhores e com a diminuição das desigualdades sociais por meio da
Educação e essas premissas atendem plenamente aos objetivos propostos pela UAB e do PACC.

O oferecimento destes cursos atende, primeiramente, a demanda e as necessidades estruturais da UEL. No entanto, possui um significado visionário ainda maior. Além de ser considerada uma ação pioneira da instituição, representa o planejamento de ações do presente e aspirações de perspectivas futuras promissoras. Estas ações fazem parte do processo educacional da instituição, aqui representada pelo NEAD/LABTED/UEL.

A experiência vivenciada nos três cursos, desde a sua concepção até a sua efetiva conclusão, nos fazem pensar que estamos no caminho certo. Sabemos que, mais importante do que trilhar a longa caminhada é dar o primeiro passo. Neste caso, já foi dado.

As ofertas não se esgotam e de acordo com as novas demandas, é perfeitamente possível oferecer novos portfólios que possam cumprir e suprir as exigências do cotidiano institucional. Desta forma, como parte do planejamento, para as novas edições 2015/2016 já foram realizadas as seguintes ofertas: Ambiente Virtual de Aprendizagem, Tutoria em EaD, Material Didático em EaD, Gestão Educacional e Tecnologias, Avaliação em EaD, Produção de Audiovisual em EaD, Produção de e-Pub e Estilos de Aprendizagem, Inteligências Múltiplas e Emocional.

Esperamos poder relatar brevemente novas ações e compartilhar com outros professores e profissionais da área, riquíssimas experiências que defrontamos nestes cursos e que defrontaremos ao longo de outros. Acreditamos que a socialização de experiências como essas podem, de forma direta ou indireta, contribuir para o desenvolvimento da Educação e por que não dizer da própria EaD no Brasil.

\section{Referências}

ALMEIDA, M. E. B. Educação, ambientes virtuais e interatividade. In: SILVA, M. (Org.). Educação online: teorias, práticas, legislação e formação corporativa. São Paulo: Loyolla, 2003. p. 201-215. 
Educação, projetos e tecnologia e conhecimento. São Paulo: PROEM, 2001.

ARAUJO, C. F.; MAQUESI, S. C. Atividades em ambientes virtuais de aprendizagem: parâmetros de qualidade. In: LITTO, M. F.; FORMIGA, M. M. M. (Org.). Educação a distância: estado da arte. São Paulo: Pearson Education do Brasil, 2009. p. 358-368.

AZZI, S. Avaliação de desempenho do aluno na EAD. 2002. Disponível em: <http://www. tvebrasil.com.br/salto/boletins 2002 /ead/ eadtxt5a.htm>. Acesso em: 24 mar. 2007.

BARBIER, R. Pesquisa-ação na instituição educativa. 18. ed. Rio de Janeiro: Zahar, 2008.

BEHRENS, M. A. Projetos de aprendizagem colaborativa num paradigma emergente. In: MORAN, J. S.; MASETTO, M. T.; BEHRENS, M. A. (Org.). Novas tecnologias e mediação pedagógica. 21. ed. Campinas: Papirus, 2013. p. 67-132.

BLIKSTEIN, P. A mente brilhante de Paulo Blikstein: depoimento. Exame, São Paulo, 2012. Disponível em: <http://exame.abril.com.br/ revista-exame/edicoes/1008/noticias/a-mentebrilhante-de-paulo-blikstein>. Acesso em: 24 mar. 2013.

BOUCHARD, P. Autonomia e distância transacional na formação a distância. In: ALAVA, S. (Org.). Ciberespaço e formações abertas. Porto Alegre: Artmed, 2001.

BRASIL. Decreto $n^{\circ} 18.110$, de 30 de janeiro de 1970. Dispõe sobre a criação da UEL como forma de Fundação. Disponível em: <httphttp:// www.uel.br/gabinete/portal/pages/arquivos/ Legislacao/Decreto\%2018110\%20-\%20Cria\%20 a\%20UEL.pdf $>$. Acesso em: 23 jun. 2015.

Decreto $n^{\circ} 29.741$, de 11 de julho de 1951. Institui uma Comissão para promover a Campanha Nacional de Aperfeiçoamento de Pessoal de Nível Superior. Disponível em: $<$ http:// legis.senado.gov.br/legislacao/ListaPublicacoes. action?id=161737>. Acesso em: 25 jun. 2015.
Ministério da Educação. Portaria $\overline{M E C}^{\circ}$ 318, de 2 de abril de 2009. Transfere à Coordenação de Aperfeiçoamento de Pessoal de Nível Superior - CAPES a operacionalização do Sistema Universidade Aberta do Brasil - UAB. Disponível em: <http:// portal.mec.gov.br/index.php?option $=\mathrm{com}$ docman\&view $=$ download \&alias $=15069$-pactodou-1-2\&Itemid=30192>. Acesso em: 25 jun. 2015.

- Ministério da Educação. Referenciais de qualidade para educação superior a distância. 2007. Disponível em: <http://portal.mec.gov. $\mathrm{br} / \mathrm{seed} /$ arquivos/pdf/legislacao/refead1.pdf $>$. Acesso em: 25 jun. 2015.

COORDENAÇÃO DE APERFEIÇOAMENTO DE PESSOAL DE NÍVEL SUPERIOR - CAPES. UAB. Chamada UAB $N^{\circ}$ 01/2013: cursos novos no Sistema Universidade Aberta do Brasil (UAB): 2013. Disponível em: <http://www.uab.capes. gov.br/>. Acesso em: 17 jul. 2015.

FUJITA, O. M. Educação a distância, currículo e competência: uma proposta de formação on-line para a gestão empresarial. 2010. Tese (Doutorado em Educação) - Faculdade de Educação, Universidade de São Paulo, São Paulo, 2010. Disponível em: <http://www.teses.usp.br/teses/ disponiveis/48/48134/tde-26042010-091608/>. Acesso em: 25 jun. 2015.

HARASIM, L. Online collaborative learning $(O C L)$ : the next generation for elearning. 2006. Disponível em: <http://www.slideshare. net/aquifolium/linda-harasim-on-onlinecollaborative-learning>. Acesso em: 9 set. 2009.

KENSKI, V. M. Tecnologias e ensino presencial e a distância. Campinas: Papirus, 2015.

LEVY, P. Cibercultura. São Paulo: Ed. 34, 1999.

LIMA, L. O. L. Mutações em educação segundo McLuhan. Rio de Janeiro: Vozes, 1998.

LUDKE, M.; ANDRÉ, M. E. D. A. Pesquisa em educação: abordagens qualitativas. 2. ed. São Paulo: EPU, 2013. 
MORAN, J. M. Laboratório on-line de aprendizagem: uma experiência de aprendizagem colaborativa por meio do ambiente virtual de aprendizagem Eurek@Kids. Cadernos Cedes, Campinas, v. 27, n. 3, set./dez. 2007. Disponível em: $<$ http://www.scielo.br/scielo.php?script=sci_ar ttext\&pid=S0101-32622007000300006>. Acesso em: 17 set. 2009.

MOTA, R.; INAMORATO, A. MOOC, uma revolução em curso. Jornal da Ciência, nov. 2012. Disponível em: <http://www.jornaldaciencia.org. br/Detalhe.jsp?id=85111>. Acesso em: 17 set. 2013.

PALlOFF, R. M.; PRATT, K. Construindo comunidades de aprendizagem no ciberespaço: estratégias eficientes para a sala de aula on-line. Porto Alegre: Artmed, 2002.

UEL-UNIVERSIDADE ESTADUAL DE LONDRINA. Núcleo de Educação a Distância [Nead]. Disponível em: <http://www.labted. net/\#!nead/ckj1>. Acesso em: 25 jun. 2015. 